\title{
Solvent free lipase catalyzed synthesis of butyl caprylate
}

\author{
MEERA T SOSE, SNEHA R BANSODE and VIRENDRA K RATHOD*(D) \\ Department of Chemical Engineering, Institute of Chemical Technology, Matunga (E), Mumbai, Maharashtra \\ 400 019, India \\ E-mail: vk.rathod@ictmumbai.edu.in
}

MS received 10 May 2017; revised 23 August 2017; accepted 24 August 2017; published online 10 November 2017

\begin{abstract}
The ester, butyl caprylate has wide applications in commercial market and it also possesses characteristic fruity flavor. The work exhibits the effect of various reaction parameters and the optimization study for the synthesis of butyl caprylate in presence of bio-catalyst. To achieve maximum conversion the optimum parameters thus established include; temperature $60^{\circ} \mathrm{C}$, mole ratio of caprylic acid and butanol as 1:2, lipase loading $2 \%(\mathrm{w} / \mathrm{v}), 250 \mathrm{rpm}$ speed of agitation and $4 \mathrm{~g}$ of molecular sieves. The immobilized enzyme was also recycled and reused for 7 cycles with only $30 \%$ loss from its initial activity. The thermodynamic parameters at different temperatures were also determined. The esterification was conducted successfully with $92 \%$ as maximum conversion in $5 \mathrm{~h}$ in a stirred batch reactor under solvent free system and in presence of molecular sieves that was used to adsorb water formed in reaction.
\end{abstract}

Keywords. Butyl caprylate; Novozym 435; caprylic acid; butanol; thermodynamics.

\section{Introduction}

Esters are chemical compounds derived from the reaction of acid and alcohol with numerous applications in various industries. ${ }^{1}$ Short-chain esters possess pleasant flavor and fragrance properties, and hence find its applications in commercial industries. In current years, the commercial market for food flavor is increasing rapidly and thus there is need for improvement of newer methods for synthesis of esters, to meet the increasing demands in the market. The worldwide market for natural flavoring agents is estimated to be 5-10 metric tons per year. ${ }^{2}$ The ester with fruity notes are widely used in the food products, beverages, cosmetic and pharmaceutical industries. ${ }^{3}$

Esterification reaction is carried out in the presence of catalyst which could be either acid or base. But the use of acid or base catalyst have disadvantage for being harmful for human consumption and may also have issues regarding food standards. The utilization of biocatalyst can offer better advantage rather the use of acid or harmful catalyst, that include higher yield and selectivity, formation of unwanted by- products and greener route of reaction. ${ }^{4}$ Numerous valuable esters have been successfully synthesized in presence of lipases as biocatalyst. $^{3,5,6}$ Lipases, Triacylglycerol hydrolases [E.C
3.1.1.3] are produced from many bacterial and fungal sources. As enzymes are produced from natural sources their cost of production and related treatments further make the enzymes costly. ${ }^{7}$ But the utilization of enzymes can be made cost effective if the same enzyme can be reused for several times. Lipases when immobilised on strong support can be recycled and reused. Also, immobilised enzymes exhibit more stability towards harsh reaction conditions like wide range of $\mathrm{pH}$ and temperatures without any decline in its activity. ${ }^{8}$

Along with ester, water is also formed in esterification reaction and with the progress of reaction continuous water production can cause hydrolysis to give back the substrates. Thus, control of water becomes crucial to prevent the backward reaction and obtain only ester. ${ }^{9}$ To push the reaction in forward pathway, good adsorbent of water like molecular sieves can be added. ${ }^{9}$

In this context, the aim of the work was to explore and optimize the reaction parameters for the synthesis of fruity flavor, butyl caprylate catalyzed by the immobilized lipase B from Candida antarctica, or Novozym 435. The reaction parameters under the study were, temperature, molar ratio of substrates, enzyme concentration, and speed of agitation. Earlier, an attempt was made to synthesis butyl caprylate catalyzed by pseudomonas P-38 with heptane as solvent which required

\footnotetext{
*For correspondence
} 
$48 \mathrm{~h}$ to obtain $75 \%$ conversion. ${ }^{10}$ From the vast literature reports, it has been perceived that this is a first attempt to synthesise butyl caprylate ester in a solvent free system catalyzed by immobilised lipase in a stirred batch reactor.

\section{Materials and methods}

\subsection{Materials}

Lipase as biocatalyst from Candida antarctica, immobilized on a macro porous resin (Novozym 435) was kindly donated as gift sample by Zytex Pvt Ltd, Mumbai. Caprylic Acid, n-butanol, potassium hydroxide, ethanol, methanol and molecular sieves $4 \mathrm{~A}^{0}$ were purchased from S.D. Fine Chemicals Pvt. Ltd., Mumbai, India. All chemicals and enzyme were used without any further modification.

\subsection{Ester synthesis}

The experimental setup consisted of conventional stirred batch reactor of internal diameter $4 \mathrm{~cm}$ and capacity of $50 \mathrm{~cm}^{3}$ which was covered with three-necked lid containing condenser for reflux and overhead stirrer with four blade impellers. The entire reactor assembly was immersed in a thermostatic water bath, which was maintained at a desired temperature with an accuracy of $\pm 1^{\circ} \mathrm{C}$. To carry out the reaction, weighed quantity (for substrate ratio 1:2) of caprylic acid $(12.5 \mathrm{~mL})$ and butanol $(14.5 \mathrm{~mL})$ were added in a reactor vessel and stirred at $250 \mathrm{rpm}$ for some time to attain homogeneity at temperature $\left(60^{\circ} \mathrm{C}\right)$. Thereafter, weighed amount of immobilised lipase as catalyst $(2 \%$ w/v i.e., $0.54 \mathrm{~g})$ was added to initiate the reaction. Molecular sieves $(4 \mathrm{~g})$ was also added in reaction mixture to adsorb water formed and prevent hydrolysis action. The total reaction volume was maintained to $27 \mathrm{~mL}$ approximately without use of any other solvent. Aliquots or samples were drawn at stipulated time interval to identify course of reaction.

\subsection{Analytical method}

The progress of the reaction was estimated by the determination of acid value titration method against $0.1 \mathrm{~N} \mathrm{KOH}$ and phenolphthalein as an indicator. The acid value of the sample was determine using formula stated as,

Acid Value $=\frac{56.1 \times V \times N}{W}$

Where, $\mathrm{N}=$ Normality of $\mathrm{KOH}$ solution $\mathrm{V}=$ Volume of $\mathrm{KOH}$ required to neutralized the acid in $\mathrm{ml}, \mathrm{W}=$ Weight of sample taken for analysis in $\mathrm{g}$

\section{Results and Discussion}

The effect of various parameters such as temperature, molar ratio of substrates, enzyme loading and stirring speed was studied by varying each parameter at a time and keeping others constant. It is also very important to prevent excess water formation as it results to give back the reactants with hydrolysis reaction. Thus, the effect of presence of molecular sieves in reaction system was studied. To illustrate the importance of molecular sieves in esterification, the experiments in presence and absence of molecular sieves under optimised reaction conditions were also conducted. It was observed that maximum conversion of $92 \%$ and $60 \%$ was obtained with addition of molecular sieves and without molecular sieves respectivley at the end of $5 \mathrm{~h}$. This is possibly due to fact that the esterification reaction is reversible reaction and removal of one of the products improves the reaction by distributing its equilibrium and increasing rate in forward direction. Thus, the molecular sieves marked as important adsorber of water and it was further used in all experiments in activated (pre-heat at $100^{\circ} \mathrm{C}$ to remove moisture) form.

\subsection{Effect of mole ratio}

The ratio of substrates is a crucial parameter of esterification reaction as the reaction have tendency to follow backward path since the reaction is reversible. It is therefore advisable to add slight higher concentration of one of the substrates to shift the equilibrium in forward pathway during every step. ${ }^{11}$ However, an excess acid concentration in enzymatic reaction does not favor the reaction condition as there is possibility of biocatalyst decay. Thus, an excess concentration of alcohol can be used without much damage to the enzyme catalyst. ${ }^{3}$ From the various experiments conducted for substrate concentration (acid to alcohol), it was observed that as alcohol concentration increased by varying ratio as $1: 1$ to $1: 2$, the final conversion also increased from $81 \%$ to $90 \%$ respectively. Figure 1 depicts the conversion with respect to caprylic acid to butanol, as the alcohol concentration is increased further i.e., molar ratio 1:3, the final conversion decreased from $92 \%$ to $85 \%$. This can be attributed to the inhibition action of alcohol on lipase. ${ }^{11}$ As the reaction is carried out in a solvent free system excess of butanol can act as polar solvent for the reaction mixture. But when the alcohol exceeds the optimum concentration, being polar in nature can strip off essential water require to the active conformation of lipase as biocatalyst. The reactions were carried out at $60{ }^{\circ} \mathrm{C}$ using thermostatic water bath with $2 \%(\mathrm{w} / \mathrm{v})$ enzyme loading of total volume. Han et al., also reported that 


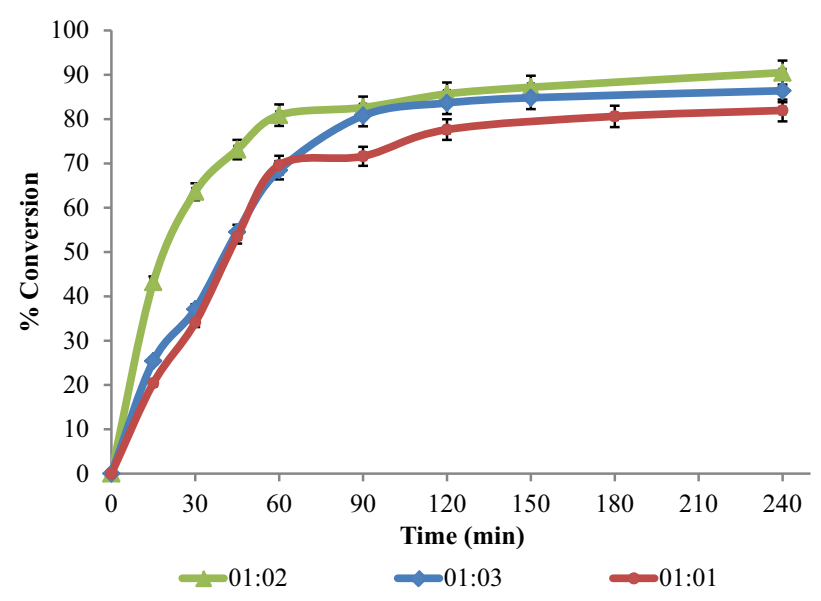

Figure 1. Effect of molar concentration of caprylic acid: butanol: Reaction conditions: speed of agitation $250 \mathrm{rpm}$; catalyst loading $2 \%(\mathrm{w} / \mathrm{v})$ of total volume; temperature $60^{\circ} \mathrm{C}$ and molecular sieves $4 \mathrm{~g}$.

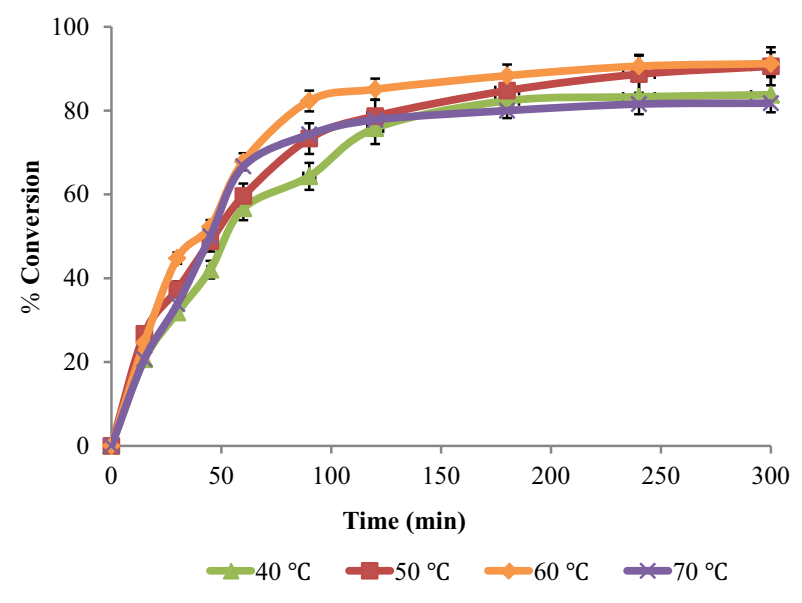

Figure 2. Effect of temperature on esterification reaction of butyl caprylate. Reaction conditions, Molar ratio of caprylic acid: butanol as 1:2, speed of agitation $250 \mathrm{rpm}$; catalyst loading $2 \%(\mathrm{w} / \mathrm{v})$, molecular sieves $4 \mathrm{~g}$.

conversion improved from mole ratio of hexanoic acid to ethanol, 1:1 to $1: 1.25$ thus implying that slight excess of alcohol in esterification favors the reaction. ${ }^{12}$

\subsection{Effect of temperature}

The temperature is significant parameter for a heterogeneous catalysed reaction since temperature of reaction induces many changes in reaction. In order to investigate the effect of temperature, esterification reactions were carried out in the temperature range of $40{ }^{\circ} \mathrm{C}$ to $70^{\circ} \mathrm{C}$ at catalyst loading $2 \%(\mathrm{w} / \mathrm{v})$, molar ratio of caprylic acid and butanol as 1:2, $4 \mathrm{~g}$ of molecular sieves and speed of agitation as $250 \mathrm{rpm}$. Figure 2 depicts an increase in the conversion with an increase in temperature. As the temperature is gradually elevated from $40^{\circ} \mathrm{C}, 50^{\circ} \mathrm{C}$,

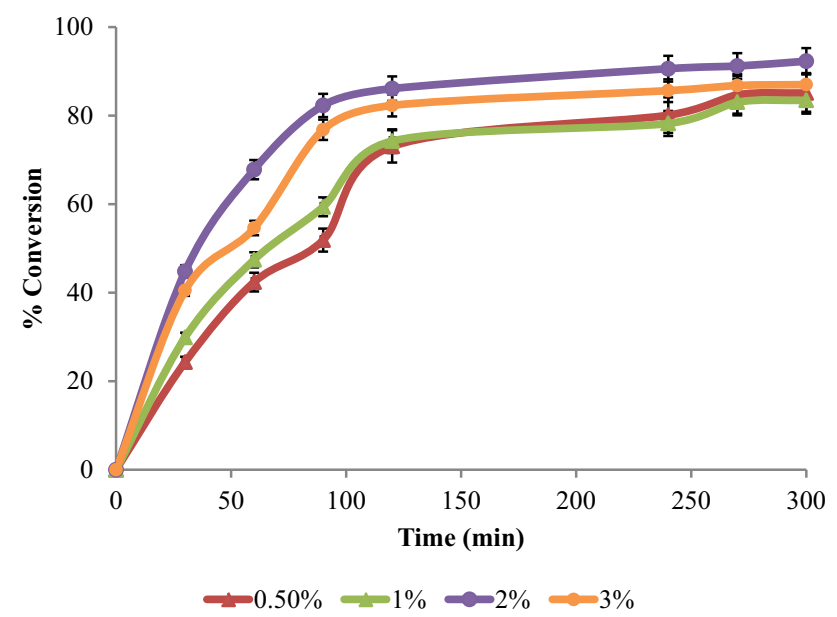

Figure 3. Effect of enzyme loading on synthesis of Butyl caprylate. Reaction conditions: molar ratio Caprylic acid: n-Butanol 1:2; speed of agitation $250 \mathrm{rpm}$; temperature $60^{\circ} \mathrm{C}$ and molecular sieves $4 \mathrm{~g}$.

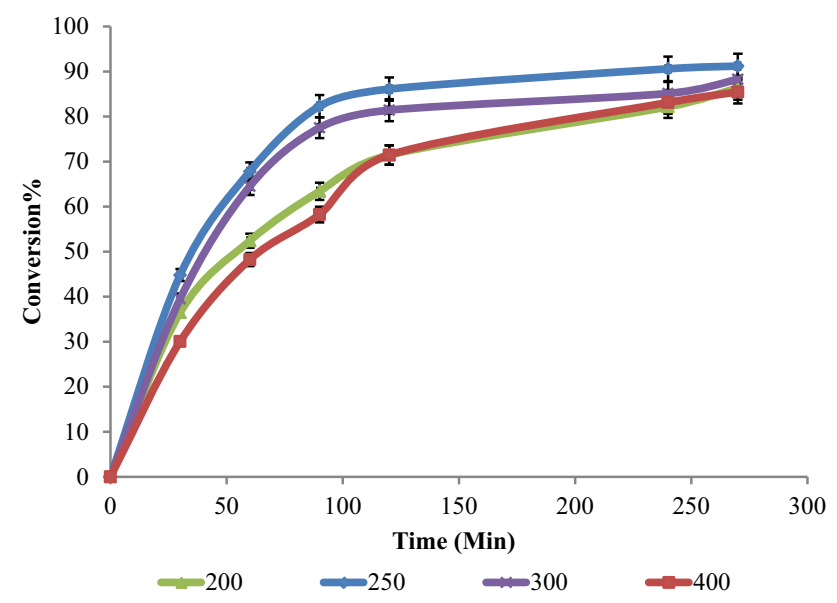

Figure 4. Effect of agitation on esterification of caprylic acid. Reaction conditions Molar ratio Caprylic Acid: n-Butanol is $1: 2$, catalyst loading $2 \%(\mathrm{w} / \mathrm{v})$, temperature $60^{\circ} \mathrm{C}$ and molecular sieves $4 \mathrm{~g}$.

and $60{ }^{\circ} \mathrm{C}$ the conversion also increased as $75 \%, 78 \%$, and $85 \%$ respectively in initial $2 \mathrm{~h}$. However, there is a marginal difference in conversion after $2 \mathrm{~h}$ till $5 \mathrm{~h}$ for all the temperatures. At higher temperatures, the rate of reaction increases because, the kinetic energy of molecules also increases which facilitates effective collisions and interaction between the substrate molecules and catalyst. ${ }^{13}$

However, at $70^{\circ} \mathrm{C}$ it was also detected that final conversion obtained was lower to that of $60^{\circ} \mathrm{C}$, which could be due to thermal deactivation of lipase. When exposed to very high temperature for prolonged period, the enzymes lose their active conformation and undergo thermal degradation. ${ }^{14}$ Thus, maximum conversion $(66 \%)$ though obtained in $60 \mathrm{mins}$ at temperature 


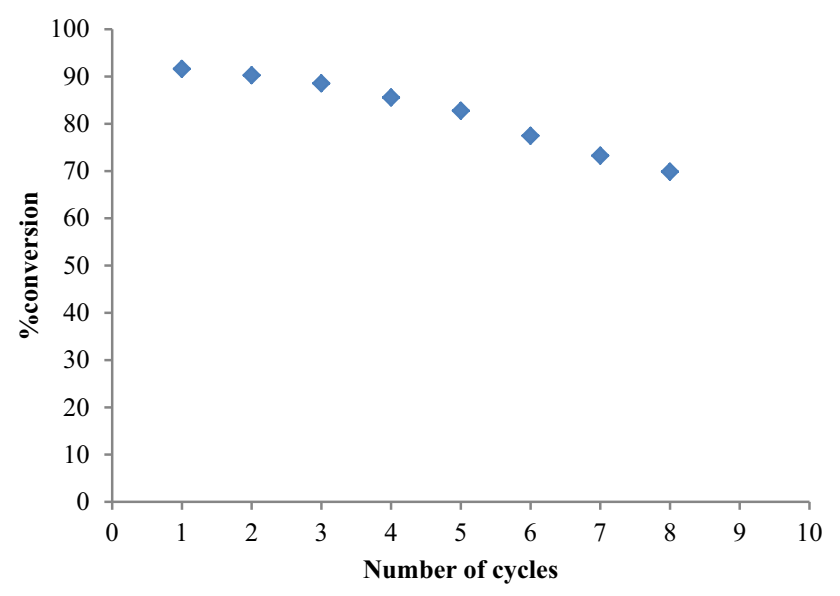

Figure 5. Reusability of immobilized lipase in solvent free condition. Reaction conditions: Mole ratio of caprylic acid to Butanol 1:2, speed of agitation $250 \mathrm{rpm}$; catalyst loading 2\% $(\mathrm{w} / \mathrm{v})$, temperature $60^{\circ} \mathrm{C}$ and molecular sieves $4 \mathrm{~g}$.

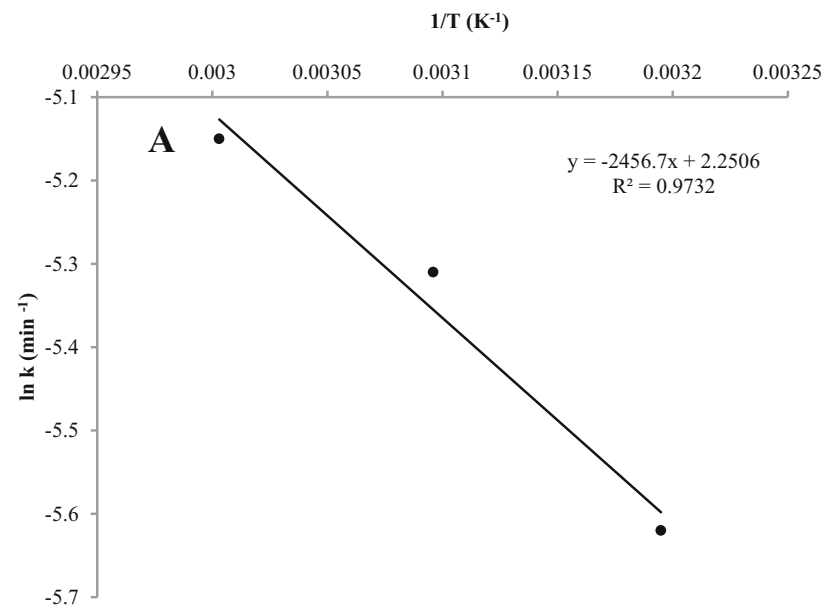

Figure 6. Arrhenius plot for Novozym 435 catalysed synthesis of butyl caprylate in solvent free system. Reaction conditions: molar ratio of caprylic acid: butanol is 1:2, catalyst loading $2 \%(\mathrm{w} / \mathrm{v})$, temperature $60^{\circ} \mathrm{C}$, speed of agitation $250 \mathrm{rpm}$ and molecular sieves $4 \mathrm{~g}$.

$70{ }^{\circ} \mathrm{C}$, with continued exposure to higher temperature, the conversion declines gradually. Although, maximum conversion of about $92 \%$ was obtained for $50{ }^{\circ} \mathrm{C}$ and $60^{\circ} \mathrm{C}$ after $5 \mathrm{~h}$, the rate of reaction was faster in the case of $60^{\circ} \mathrm{C}$. Thus, considering the fact that the lipase gave the higher activity at $60^{\circ} \mathrm{C}$, it was determined as optimum temperature. The synthesis of cinnamyl laurate catalyzed by Novozym 435 also reported $60^{\circ} \mathrm{C}$ as optimum temperature and conversion achieved was $75 \%$ in 2 h. $^{15}$

\subsection{Effect of catalysts loading}

Enzymes as biocatalyst are mostly preferred over other catalyst since there is formation of desired product with minimized production of by-products under mild reaction conditions. ${ }^{16}$ To attain excellent stability and reactivity, the enzymes are immobilised on porous support that increased the cost of enzymes. Thus, considering the cost and advantages of lipase it is necessary to optimise the concentration of catalyst. The amount of catalyst loading was studied in the range of $0.5 \%$ to $3 \%(\mathrm{w} / \mathrm{v})$. It is found that with an increase in catalyst loading, the conversion of caprylic acid increased with proportional increase in the number of active sites. ${ }^{17}$ Figure 3 indicated that the conversion was highest at $2 \%(\mathrm{w} / \mathrm{v})$ and at $3 \%$ and the conversion started to decline slightly after $120 \mathrm{~min}$. This would suggest that substrate molecules are limiting and all the molecules are attached to the active sties. Any further increase in enzyme loading will have no effect on conversion as no substrate molecules are available. ${ }^{18}$ Thus, beyond optimized condition of catalyst loading, there was no substantial increase in final conversion. But with an increase in enzyme concentration there is inefficient mixing that limits the mass transfer, effectual contact and diffusion of substrates and enzyme that cause conversion rate to decrease. ${ }^{19}$ Agglomeration of immobilised lipase and inefficient exposure of surplus enzyme active sites is also responsible for lower conversions at higher lipase loading. ${ }^{14}$

\subsection{Effect of speed of agitation}

In the case of immobilized enzyme, the reactants have to diffuse from the bulk liquid to the external surface of the particle and from there into the interior pores of the catalyst where the actual reaction takes place and products are being formed. Further, the products need to diffuse out from the enzyme particles to the bulk liquid. External mass transfer limitations can be minimized by carrying out the reaction at an optimum speed of agitation and low enzyme loading. ${ }^{20}$ To understand the influence of speed of agitation experiments were carried out in the range of 200-400 rpm (Figure 4). As speed of agitation increased from 200 to $250 \mathrm{rpm}$, the conversion was found to increase from $85 \%$ to $92.25 \%$. However, the conversion decreased at 300 and $400 \mathrm{rpms}$ to 85 and $88.04 \%$ respectively. Increase in conversion and initial rate with the speed of agitation from 200 to $250 \mathrm{rpm}$ was due to decrease in mass transfer resistance at higher turbulence. However, the decrease in the conversion at $400 \mathrm{rpm}$ can be reasoned by the shearing effect on enzyme at higher stirring speed and physical loss of enzyme due to removal of enzyme from the support. It has also been observed that at $300 \mathrm{rpm}$ enzyme begin to leave its support with prolonged time thus losing its recyclability. ${ }^{21}$ The synthesis of biodiesel from waste 
Table 1. The determination of Thermodynamic parameters at different temperatures.

\begin{tabular}{lccc}
\hline Parameter & \multicolumn{3}{c}{ Temperature $(\mathrm{K})$} \\
\cline { 2 - 4 } & 313 & 323 & 333 \\
\hline Enthalpy Change, $\Delta \mathrm{H}\left(\mathrm{kJ} \mathrm{mol}^{-1}\right)$ & 17.822 & 17.739 & 17.656 \\
Entropy Change, $\Delta \mathrm{S}\left(\mathrm{kJ} \mathrm{mol}^{-1} \mathrm{~K}^{-1}\right)$ & -0.2920 & -0.2897 & -0.2884 \\
Free energy change, $\Delta \mathrm{G}\left(\mathrm{kJ} \mathrm{mol}^{-1}\right)$ & 109.2294 & 111.3127 & 113.6936 \\
\hline
\end{tabular}

cooking oil catalyzed by Novozym 435 was similarly performed in the range of 200 to $300 \mathrm{rpm}$, as there was significant decline in activity of lipase at high agitation speed of $400 \mathrm{rpm}$ and more due to shear stress and attrition. ${ }^{22}$ Therefore, stirring speed of $250 \mathrm{rpm}$ was selected as optimum for the esterification reaction keeping all other parameters constant.

\subsection{Enzyme reusability study}

As cost is a major concern of enzymatic reactions, immobilised enzymes can be recycled and reused if the activity of biocatalyst is retained. The biocatalyst used in the first reaction mixture was first recovered by filtration, further washed with hexane, dried at $40^{\circ} \mathrm{C}$ for $2 \mathrm{~h}$ and reused for successive batches. Washing the catalyst is a vital step during recycle of lipase because immobilised lipase being bound to porous support there is possibility of substrate or product residues adhering to the inner pores or the surface of lipase which make the active sites unavailable temporarily. ${ }^{23}$ The presence of acid near or around the lipase not only blocks the active sites but also degrades the activity of catalyst. ${ }^{24}$ Additionally inevitable loss of enzyme during filtration due to attrition caused by stirred batch reactor. Figure 5 signifies the reusability studies conducted at optimum reaction parameters and it is evident that the biocatalyst under the study was reused up to 8 successive cycles with loss to $42 \%$ from initial activity. It was also observed that there was only marginal decrease in the conversion after each cycle which reveals the robustness of catalyst considering industrial applications. Martins et al.,${ }^{24}$ also reported that for synthesis of butyl acetate at $45^{\circ} \mathrm{C}$, Novozym 435 could be reusable and retain $70 \%$ of its initial activity for 6 cycles when washed with hexane. Also, reusability of Novozym 435 in solvent free system experiments conducted for synthesis of isobutyl propionate showed that it was reusable for 6 cycles. ${ }^{25}$

\subsection{Determination of thermodynamic parameters}

To determine the thermodynamics parameter of the reaction under study, the energy of activation and related parameters were deduced at different temperatures. The energy of activation is the energy required for formation of a transition state to the product. The value of activation energy is positive in terms of enzymatic reactions and it was found as $20.425 \mathrm{~kJ} \mathrm{~mol}^{-1}$ which is close to the activation energy reported for the esterification of free fatty acids catalyzed with Pseudomonas

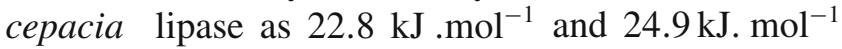
with Thermomyces lanuginosus lipase. ${ }^{26}$ The relation for temperature dependent rate constant can be evaluated from Arrhenius law:

The Arrhenius plot of $\ln (\mathrm{k})$ vs $1 / \mathrm{T}$ for the same is depicted in Figure 6. From the plot, value of (-Ea/R) and $\ln (\mathrm{A})$ can be calculated as slope and y-intercept respectively.

The thermodynamic parameters that are state functions are change in enthalpy $(\Delta \mathrm{H})$, change in entropy $(\Delta S)$ and Gibb's free energy change $(\Delta G)$ and they depend on the initial state and final states and not the manner of existence of the system or states. ${ }^{26} \Delta \mathrm{H}$ signifies the amount of heat absorbed or liberated and $\Delta S$ shows the randomness or disorderedness of a reaction and $\Delta \mathrm{G}$ characterizes the change in energy consumed by the system at constant temperature and pressure in spontaneous reaction. ${ }^{27}$ The thermodynamic constants were further derived from Eyring equation.

The calculated change in all the mentioned thermodynamic parameters are represented in Table 1. There is loss of entropy during the formation of enzymesubstrate [ES] complex with liberation of rotational and translation energies and therefore the entropy is expressed as negative value. The entropy $\Delta \mathrm{S}$ calculated at $323 \mathrm{~K}$ was $-0.289 \mathrm{~kJ} \mathrm{~mol}^{-1} \mathrm{~K}^{-1}$ and it signified that [ES] complex formation was spontaneous as outcome of mostly successful collisions. The $\Delta \mathrm{G}$ calculated at different temperatures was almost similar and in the range of $110-113 \mathrm{~kJ} \mathrm{~mol}^{-1} .^{19}$

\section{Conclusion}

Butyl caprylate ester was successfully synthesized under solvent-free system using caprylic acid and 
butanol as substrates in presence of Novozym 435 catalyst. The study also comprised optimization of reaction conditions including effect of mole ratio, temperature, catalyst loading, reusability of enzyme and speed of agitation. Molecular sieves also proved as an effective alternative in adsorbing the water formed in reaction mixture as by-product. The energy of activation of the esterification reaction was deduced as $20.425 \mathrm{~kJ} . \mathrm{mol}^{-1}$ and other thermodynamic parameters were also determined at different temperatures for the reaction under optimum conditions. Enzyme used for the system is very effective as it can be recycled without loss of activity.

\section{References}

1. Chowdary G V, Ramesh M N and Prapulla S G 2000 Enzymic synthesis of isoamyl isovalerate using immobilized lipase from Rhizomucor miehei: a multivariate analysis Process Biochem. 36331

2. Gubicza L, Kabiri-Badr A, Keoves E and Belafi-Bako K 2001 Large-scale enzymatic production of natural flavour esters in organic solvent with continuous water removal J. Biotechnol. 84193

3. Romero M D, Calvo L, Alba C and Daneshfar 2007 A kinetic study of isoamyl acetate synthesis by immobilized lipase-catalyzed acetylation in n-hexane J. Biotechnol. 127269

4. Corradini M C, Costa B M, Bressani A P P, Karen C, Garcia A, Pereira E B, Mendes A A and Carolina M 2017 Improvement of the enzymatic synthesis of ethyl valerate by esterification reaction in a solvent system Prep. Biochem. Biotechnol. 47100

5. Chowdary G and Prapulla S 2005 Kinetic study on lipasecatalyzed esterification in organic solvents Ind. J. Chem. 442322

6. Anschau A, Aragão V C, Porciuncula B D A, Kalil S J, Burkert C A V, Burkert J F M 2011 Enzymatic synthesis optimization of Isoamyl butyrate J. Braz. Chem. Soc. 22 2148

7. Hari Krishna S, Divakar S, Prapulla S G and Karanth N G 2001 Enzymatic synthesis of isoamyl acetate using immobilized lipase from Rhizomucormiehei J. Biotechnol. 87193

8. Iyer P V, Ananthanarayan L 2008 Enzyme stability and stabilization-aqueous and non-aqueous environment Process Biochem. 431019

9. Giacometti J, Giacometti F and Vasic-racki D K 2001 Kinetic characterisation of enzymatic esterification in a solvent system: adsorptive control of water with molecular sieves J. Mol. Catal. B: Enzym. 9921

10. Tan S, Owusu Apenten R K and Knapp J 1996 Low temperature organic phase biocatalysis using cold-adapted lipase from psychrotrophic Pseudomonas P38 Food Chem. 57415

11. Krishna S H and Karanth N G 2001 Lipase-catalyzed synthesis of isoamyl butyrate: a kinetic study Biochim. Biophys. Acta 1547262
12. Han S-Y, Pan Z-Y, Huang D-F, Ueda M, Wang X-N and Lin Y 2009 Highly efficient synthesis of ethyl hexanoate catalyzed by CALB-displaying Saccharomyces cerevisiae whole-cells in non-aqueous phase $J$. Mol. Catal. B: Enzym. 59168

13. Rodriguez-Nogales J M, Roura E and Contreras E 2005 Highly efficient synthesis of ethyl hexanoate catalyzed by CALB-displaying Saccharomyces cerevisiae wholecells in non-aqueous phase Process Biochem. 4063

14. Balen M, Silveira C, Kratz J M, Simoes C M O, Valerio A, Ninow J L, Nandi L G, Di Luccio M and de Oliveira D 2015 Novozym ${ }^{\circledR} 435$-catalyzed production of ascorbyl oleate in organic solvent ultrasound-assisted system Biocatal. Agric. Biotechnol. 4514

15. Yadav G D and Dhoot S B 2009 Immobilized lipasecatalysed synthesis of cinnamyl laurate in non-aqueous media J. Mol. Catal. B: Enzym. 5734

16. Mateo C, Palomo J M, Fernandez-Lorente G, Guisan J M and Fernandez-Lafuente R 2007 Improvement of enzyme activity, stability and selectivity via immobilization techniques Enzyme Microb. Technol. 401451

17. van Beilen JB and Li Z 2002 Enzyme Technology: an overview Curr. Opin. Biotechnol. 13338

18. Bansode S R and Rathod V K 2014 Ultrasound assisted lipase catalysed synthesis of isoamyl butyrate Process Biochem. 491297

19. Bansode S R, Hardikar M A and Rathod V K 2016 Evaluation of reaction parameters and kinetic modelling for Novozym 435 catalysed synthesis of isoamyl butyrate $J$. Chem. Technol. Biotechnol. 91306

20. Yadav G D and Devi K M 2004 Immobilized lipasecatalysed esterification and transesterification reactions in non-aqueous media for the synthesis of tetrahydrofurfuryl butyrate: comparison and kinetic modelling Chem. Eng. Sci. 59373

21. Yadav G D and Lathi P S 2003 Kinetics and mechanism of synthesis of butyl isobutyrate over immobilised lipases Biochem. Eng. J. 16245

22. Gharat N and Rathod V K 2013 Enzyme catalyzed transesterification of waste cooking oil with dimethyl carbonate J. Mol. Catal. B: Enzym. 8836

23. Gawas S D, Jadhav S V and Rathod V K 2016 Solvent Free Lipase Catalysed Synthesis of Ethyl Laurate: Optimization and Kinetic Studies Applied Biochem. Biotechnol. 71428

24. Martins A B, Graebin N G, Lorenzoni A S G, FernandezLafuente R, Ayub M A Z and Rodrigues R C 2011 Rapid and high yields of synthesis of butyl acetate catalyzed by Novozym 435: Reaction optimization by response surface methodology Process Biochem. 462311

25. Kuperkar V V, Lade V G, Prakash A and Rathod V K 2014 Synthesis of isobutyl propionate using immobilized lipase in a solvent free system: optimization and kinetic studies J. Mol. Catal. B: Enzym. 99143

26. Sharma A, Dalai A K and Chaurasia S P 2015 Thermodynamic study of hydrolysis and esterification reactions with immobilized lipases Eur. Int. J. Sci. Technol. 4128

27. Waghmare G V and Rathod V K 2016 Ultrasound assisted enzyme catalyzed hydrolysis of waste cooking oil under solvent free condition Ultrason. Sonochem. 32 60 